science which deals with the diseases of cultivated plants. Fourth, those which destroy other property ; in this category are the insects attacking furs, woollen goods, etc., and the food stuffs, which belong to domestic economy and at the saine time to commerce; library insects belong to library economy and so on. Fifth, those directly beneficial to man, which includes the bee, the silk worm, etc., industries which form one of the primary divisions of agriculture. Sixth, those indirectly beneficial to man by destroying the injurious insects; these in- sects of course belong to the sciences that consider the insects which are their victims.

Finally, to recapitulate, scientific entomology is a department of biology, economic entomology of agriculture. They have all the difference between them that there is between a pure science and an economic science. Can we as a society include them both? I think we should not. On the other hand the economic entomologists are nearly all at the same time scientific entomologists. These we can and do welcome.

\title{
A LIST OF THE ORTHOPTERA OF ILLINOIS.-II.
}

\author{
BY JEROME MCNEILL, FAYETTEVILLE, ARK.
}

\section{LOCUSTIDAE.}

19. Scudderia curvicauda De Geer. This is an abundant species in Illinois in suitable localities. Its favorite haunt is the wild meadows and prairies covered with coarse grasses and weeds. It is the only one of the katydids that flies freely in the daytime. It is in fact crepuscular rather than nocturnal. It may be seen flying at any hour of the day, but its note is not generally heard until the middle of the afternoon. The note cannot be supposed to represent more than the first two syllables of the "Ka-ty-did" or "Ka-ty-did-n't" of its congeners. It is made but once and the rasping jerky sound has been very well represented by $\mathrm{Mr}$. Scudder as bzrrin. It has been found at Moline as early as the 2 Ist of July.

20. Scudderia fuscata Brunner. This species is more abundant than the last but it too must be looked for in the right place. It is even less domestic in its habits than curvicauda. The latter is sometimes found about houses and gardens in town but the former is almost never seen in town. It may be looked for in the shrubs and undershrubs of open woods and clearings and in weedy fields and meadows. Its note is indistinguishable from that of curvicauda but it is much less frequently heard. The earliest recorded date of its capture at Moline is August 4th.

21. Amblycorypha oblongifolia De 
Geer. This species like the last is partial to shrubs but it is much more common in the vicinity of houses in towns. Its note is a quick shuffling sound which resembles "Katy" or "Katy-did" very slightly. It sometimes flies in the evening but much more rarely than $S$. curvicauda. It makes its appearance in the neighborhood of Moline about the first of August.

22. A. rotundifolia Scudder. This species resembles the preceding in song and habits. In northern Illinois it makes its appearance about the tenth of August.

23. Microcentrumlaurifolium Linn. I have never captured this species at Moline nor have I heard its note there, which may be represented by the syllable " $t i c$ " repeated from eight to twenty times at the rate of about four to the second. It is a tree-loving species, very common in Missouri, according to Riley, and therefore presumably common in southern Illinois.

24. Cyrtophyllus concavus Harr. This is the true "Katydid," common wherever there are trees. Its song is better known and the insect itself less known, because of its arboreal habits, than either of the other katydids. This species moves about so little that it is not unlikely that in many cases an individual spends its whole life upon a single tree. I have listened to the song of one katydid on a certain tree every evening for more than two months. I have noticed repeatedly that on any evening when they are singing there are the same number of individuals, as indicated by the number of songs. Of all the specimens I have collected on the ground or had presented to me, probably a dozen, only a single one was a male. I have collected in sweepings hundreds of specimens of the young of Scudderia and Amblycorypha but not one of Microcentrum or Cyrtophyllus; but if Microcentrum does not leave the trees when in the larval and pupal stages it certainly does when it reaches maturity. It is then a great wanderer, coming frequently to the electric light. I have never known Cyrtophyllus to come to a light. So far as I know this is the only species of Orthoptera in which the male is not smaller and more active than the female. It is the only green, winged Locustid with which I am acquainted that does not have the wings longer than the elytra. These facts are not improbably mutually related. It may be surmised that, in the evolution of species, the katydid that developed in the greatest degree its musical apparatus had the least need of hunting up his partner when the mating season came round, and as it was so well protected by its form and color and arboreal habits as to have little need of wings, these organs have gradually degenerated into a musical and protective apparatus. As the male was released from the necessity of hunting up the female, he would naturally lose after a time his slighter but more active body : it is easy to see how arboreal habits once acquired may react upon the entire organization. If at first glance it seems strange that two species so much alike as Oecanthus niveus and Oecanthus 
fasciatus should differ so much in singing habits, the latter singing as constantly in daytime as at night, while the former is strictly nocturnal in its song, we have only to consider, in order to remove the difficulty, that fasciatus, being terrestrial, is not easily exposed by his song to the attack of birds, while niveus would inevitably be discovered should he venture to sing when his bird enemies were most active. This consideration will explain equally well, of course, why the arboreal katydids, Microcentrum, Amblycorypha and Cyrtophyllus, are silent in the day time and why the only one of the group that sings in the day time is terrestrial rather than arboreal. The case of Conocephalus robustus offers a still better illustration of the truth of this theory. This species lives both upon trees and in the grass; but while its song may be heard in the grass while the sun is high, I have never heard it from trees until after dark.

25. Conocephalus ensiger Harr. This species is common in Northern Illinois from the first of August until frost. It occurs as frequently along the weedy roadsides and in the gardens of suburbs as in the country. Its song is a loud rasping $z i p$-zip-zip repeated indefinitely. It does not hegin to sing until dark.

26. Conocephalus nebrascensis Bruner. Is a less common species than the preceding; not reported farther east than Illinois, but occurring as far west as Nebraska. It is more shy in its habits than ensiger, never being found, so far as I am aware, about the streets of a town. Like both of the other species occurring here it seems to have a great liking for Johnston grass, a species of Andropogon; but it is by no means particular in its habitat, as it may be found in little colonies in weedy or grassy places throughout the locality it inhabits.

If ensiger may be said to sing the first part of the song of Orchelimum vulgare, the well-known zipp-zip-zipp-ze-e-e-e,nebrascensis may be said with equal truth to sing the last part of the song, that represented by the $z e-e-e-e$; but the sound is much more resonant, being really in quality much more like the song of a Cicada, but not so loud and without a swell. It begins to sing earlier in the evening than ensiger.

27. Conocephalus robustus Scudd. My cabinet contains a single specimen of this species captured on the sand-hill referred to below. Its song is indistinguishable from that of dissimilis. The specimen mentioned above was captured the 28th of August.

All the species of Conocephalus seem to possess more intelligence than is usual in Orthoptera and they are about the most difficult of the order to approach. In escaping they usually slip or fall into the grass instead of jumping or flying; but they seem to fully understand that they are very well protected by their color and form. If approached very cautiously they often remain quite still upon the stem of grass upon which you have surprised them with the usually well-founded expectation that you will not be able to distinguish them from 
the green herbage around. If they think it worth while to make some active movement to escape, they will frequently slip round on the other side of the stem and walk down to the ground or off upon another plant. Unlike most Orthoptera they do not use their front legs in holding to the mouth the thing upon which they feed. Instead of biting they seem to wrench or tear away pieces from the stems or leaves.

28. Thyreonotus pachymerus Burm. This is the first Orthopteron hatched in the spring in northern states. It may be easily recognized by the gray top and shining black sides of its pronotum and by its very long and slender antennae. Very little seems to be known of its habits, but in captivity it shows a decided taste for animal food, and it may be not unreasonable to suppose that it is at least partly carnivorous in the wild state. It is found usually in shaded ravines, upon the bare ground or the trunks of trees or under rotten logs. First appearance, Aug. 9.

29. Xiphidium fasciatum De Geer. Abundant everywhere, in blue-grass meadows especially. Its song is a faint echo of that of Orchelimum vulgare with the " $z i p$-zip" omitted. It is, I believe, the first of the green grasshoppers to reach maturity and its faint little quaver is the first note of the great chorus that sounds in all the meadows from the first of August until the first of October or until cold weather. I have captured this species as early as the first of July.

30. Xiphidium brevipenne Scudd. This is a much less common species than the preceding but it is not rare in damp meadows. It first appears here about the middle of August.

31. Xiphidium ensiferum Scudd. I have obtained numerous specimens about Moline which I refer to this species with certainty, but in many cases I have the greatest difficulty in deciding whether others should be referred to this or the preceding or still other species. Both species apparently may have the under side of the posterior femora armed with spines and both seem to have forms in which there is a peculiar modification of the grasping organs of the male. Further study may enable me to tell certainly whether they are two or more or only one species. I have two forms which I place here that have wings and elytra extending much beyond the knees.

32. Xiphidium sp.? A single specimen which is apparently deformed has the ovipositor growing out of the upper side of the apex of the abdomen with the convex side up. In shape and size it resembles the preceding species but the ovipositor is curved instead of straight and two and one half times as long as the body.

33. Xiphidium strictum Scudd. Not rare in places similar to those frequented by brevipenne and ensiferum. It is found from the first of August to the middle of October or later. My cabinet contains a single specimen of this species with elytra extending to the knees and with the wings .25 of an inch longer.

34. Xiphidium nemorale Scudd. 
This is a wood species. It is found most commonly on sparsely wooded and rather barren hillsides. It is almost equal in size to strictum. The elytra of the males are unusually ample although not longer than the abdomen and the veins of the stridulating apparatus are conspicuously large. The song is louder than that of fasciatum; it consists of two parts, the first a short abrupt note which is very well represented by the syllable zip, the second is the familiar $z e-e-e$ which lasts about half a second and is made from one to five times; the $z i p$ is not repeated. I have not found it at Moline earlier than $\mathrm{Au}$ gust 2oth.

35. Orchelimum vulgare Harr. Abundant throughout the State. I have heard its note as early as the 21 st of July. Its song is the familiar $z i p-z i p$ $z i p$-zip, ze e-e-e-e. The staccato first part is repeated about four times, usually about twice a second; the ze-e-e-e continues from two or three to twenty or more seconds.

36. Orchelimum glaberrimum Burm. This species is very like the last and is very probably nothing more than a variety of vulgare. While it seems to be constintly larger and more robust it has the same form of pronotum. The wings are of the same length relative to the elytra, the posterior fumora are similar in form, relatively of the same size, and destitute of spines on the under side. The two stripes on the disk of the pronotum are not uncommon in vulgare. I have a single specimen from Effingham county, which is south of the center of the State.
37. Orchelimum longipenne Scudd. This species, if I have correctly determined it, is very like vulgare with long wings. It has, however, proportionally shorter legs, longer wings, with the elytra considerably shorter than the wings instead of equalling them as in vulgare. It is much less common than the last mentioned species but it is not rare and is found in similar situations at the same time.

38. Orchelimum concinnum Scudd. I have a number of specimens which I refer to this species though the females with one or two exceptions differ in coloration in a marked manner from typical specimens. The specimens referred to are almost completely infuscated with the elytra lighter or even green apically and the tarsi distinctly green. But one specimen, a male, has the brown stripe extending down over the face. I have captured them as early as the second week in August. They are partial to low, damp or swampy meadows.

39. Orchelimum nigripes Scuid. This handsome species is about as common at Moline as vulgare. It is not at all shy but is likely to be found in the grass or shrubbery about the house. It even shows a preference, I have thought, for human society. During the past summer an instance came under my observation of one keeping a place over the wooden finish of a doorway for more than a week. If he ate during that time he must have been obliged to leave his post to satisfy his hunger, and he probably returned many times to the place. The song is difficult to distin- 
guish with certainty from that of vulgare but usually the $z i p$ - $z i p$ is repeated only once or twice very rapidly and the $z e-e-e-e-e$ does not continue so long. The earliest recorded date for it here is the Ist of August.

40. Orchelimum silvaticum n. sp. A species occurs here not very rarely that I have thought until recently to be $O$. agile De Geer, but a careful comparison with typical specimens of that species shows so many points of difference that I think they should be considered specifically distinct.

Length of body $\delta 70 \% .70$; length of elytra $\delta .60$ to $.70 \% .56$ to .70 ; length of posterior femora $\delta .59+.59$; length of antennae $\delta \& 22$; length of ovipositor $q .32$. Very similar to agile but different in the following particulars: The elytra and wings are shorter and in the male, at least, the latter do not exceed the former. The posterior femora are relatively shorter and less attenuated apically though similarly armed with about three small spines on the under side of the apical half. The pronotum is conspicuously larger and the lateral lobes are decidedly wider at the humeral sinus. The brownish stripes on the disk of the pronotum are more remote from each other. In the proportions of the body, pronotum, hind femora, wings and elytra this species approaches vulgare much more closely than agile but it can be separated at once from the former by the presence of the spines on the under side of the hind femora.

I found this Orchelimum first on corn afterwards more commonly in open placcs in woods. Its stridulation is quite distinct from that of vulgare. It consists of the same two elements but the $z i p$ is repeated many times very rapidly so as to make almost a continuous sound and the $z e-e \cdot e-e$ is comparatively short and very constant lasting about eight seconds. The first part of the song lasts from three to five seconds. I have not taken this species before the $7^{\text {th }}$ of Sep ember.

41. Orchelimum volantum $\mathrm{n}$. $\mathrm{sp}$. A second species occurs here which I think has not been described unless I am mistaken in my identification of longipennis. In this case the supposed new species might be the latter. The specimens which I refer to longipennis agree in every particular with the description of that species and the new species does not agree in the characters given and it has so many characters strikingly different from any Orchelimum that I know that I think there can be little risk in making a synonym if I describe it.

Length of body, $\delta .72 \uparrow 1.04$; length of elytra $\delta$ I $q$ I.40; length of wings $\delta$ I.I2 $q 1.50$; length of posterior femora $\delta .66$ 우 .88 ; length of antennae $\delta 2.25 \quad 2.50$; length of ovipositor .44. The general color is green with the usual brown band on the head and pronotum very incomplete. On the disk of the pronotum it divides into two stripes which form almost a complete ellipse enclosing a short stripe on the front part of the disk while on the posterior part these stripes diverge but do not extend beyond the principal sulcus. The pronotum is of medium size, with the lateral lobes well rounded on their lower border and the humeral sinus deep. The vertex is decidedly turned up at the tip and the occiput is flat so that the top of the head is strongly concave. The elytra and wings are very long and narrower in propurtion than in any 
other Orchelimum. The elytra are so strongly reticulate that they look rough. In the female they are peculiar in having the anal field form a distinct angle (as in Scudderia) with the rest of the elytra. In the male they are peculiar in that the posterior vein of the stridulating apparatus is transverse instead of oblique as in the other species and only half the length of the adjacent vein on the right instead of twice as long as it is usually. The posterior femora are slender and armed below on the posterior half with several small spines. The ovipositor of the female is long, slightly curved on its upper side and slenderly acute.

This very marked and handsome species I found on the banks of Rock River near Cleveland in Henry County. The specimens upon which this description is basedwere found in a clump of rank growing Sagittaria variabilis which grew in the angle of an old wall that had once formed a part of the foundation of a mill. A peculiarity in the stridulation attracted my attention and led to the discovery of this as well as the preceding species. I was passing this forementioned clump of weeds in a canoe when the peculiar stridulation fell upon my ear and I at once proceded to investigate the cause. These specimens, unlike any Orchelimum with which I am acquainted, flew about from one broad leaf to another. The song has a new note in it. It may be represented as follows: zip-zip kr-ze-e-e kr-ze-e-e, the last part of the song not lasting more than a half to three quarters of a second and is always preceded by the sound which I represent imperfectly by $k r$. I have found this species in no other place and it must be very rare as its unusual note would have betrayed it to me if I had ever been near it. Two males and two females taken August rgth.

41. Udeopsylla nigra Scudd. I have found this species not uncommon in woods from the first to the middle of June.

42. Ceuthophilus maculatus Say. A rare species at Moline, a few specimens taken in June.

43. Ceuthophilus latens Scudd. Not uncommon in the latter part of June.

44. Ceuthophilus niger (?) Scudd. I have a single immature specimen which I refer to this species.

45. * Ceuthophilus gracilipes Scudd. Mr. S. H. Scudder gives Southern Illinois as a locality for this species. I have not identified it.
MARINe Insects. Those interested in this somewhat restricted field will find in last year's Revue biologique of Lille an interesting contribution to the subject by Prof. R. Moniez, entitled Acariens et insectes marins des côtes du Boulonnais. Six species of Thysanura of four genera, one of Coleoptera (Micralymma) and one of Diptera (Chironomus) are recorded.
The trustees of Dartmouth college have recently established in the agricultural department a chair of entomology and zoölogy, and filled it by the election of Dr. Clarence $M$. Weed, now in charge of the entomological department of the Ohio Experiment Station at Columbus. Professor Weed is also editor of the entomological department of the American naturalist. 

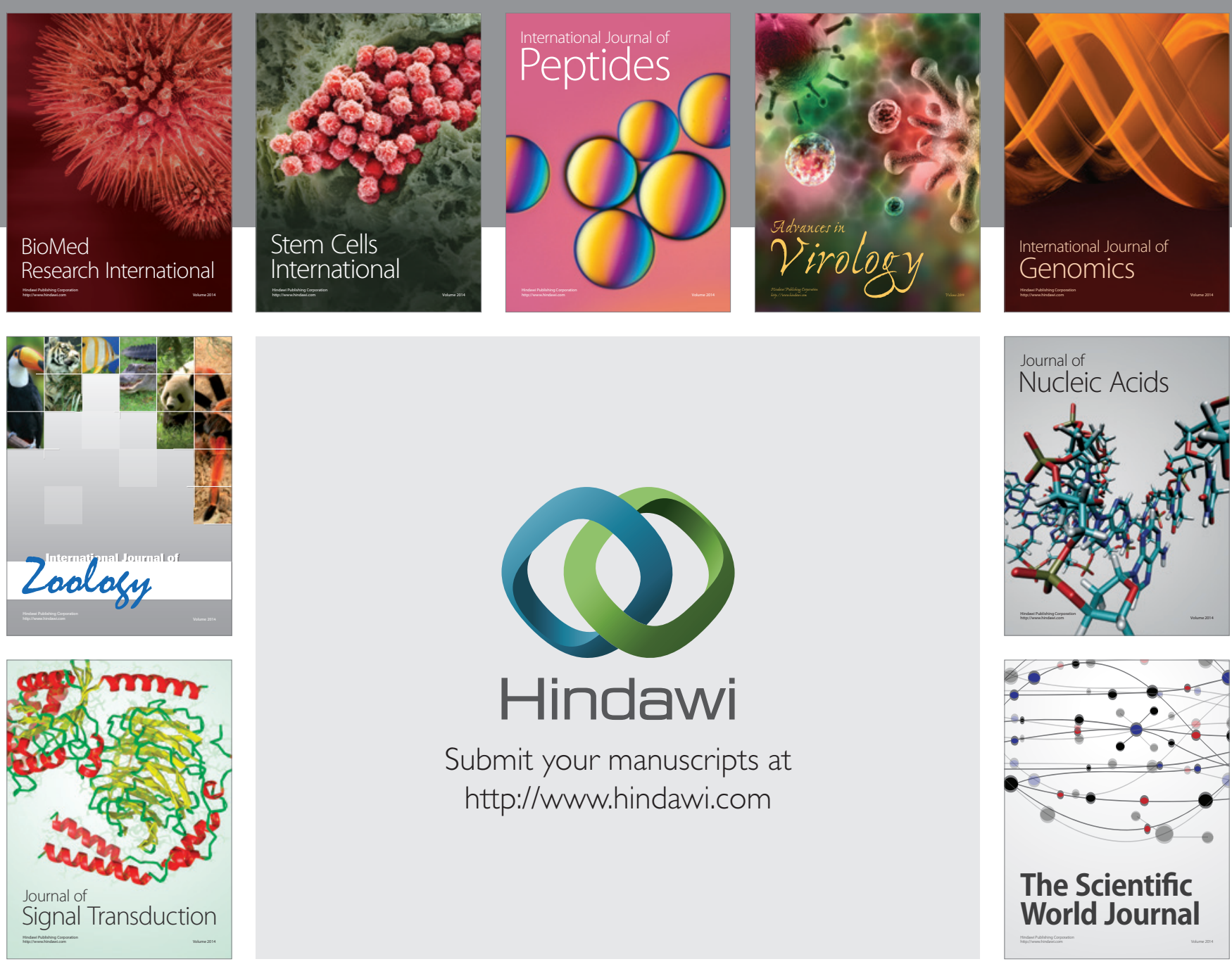

Submit your manuscripts at

http://www.hindawi.com
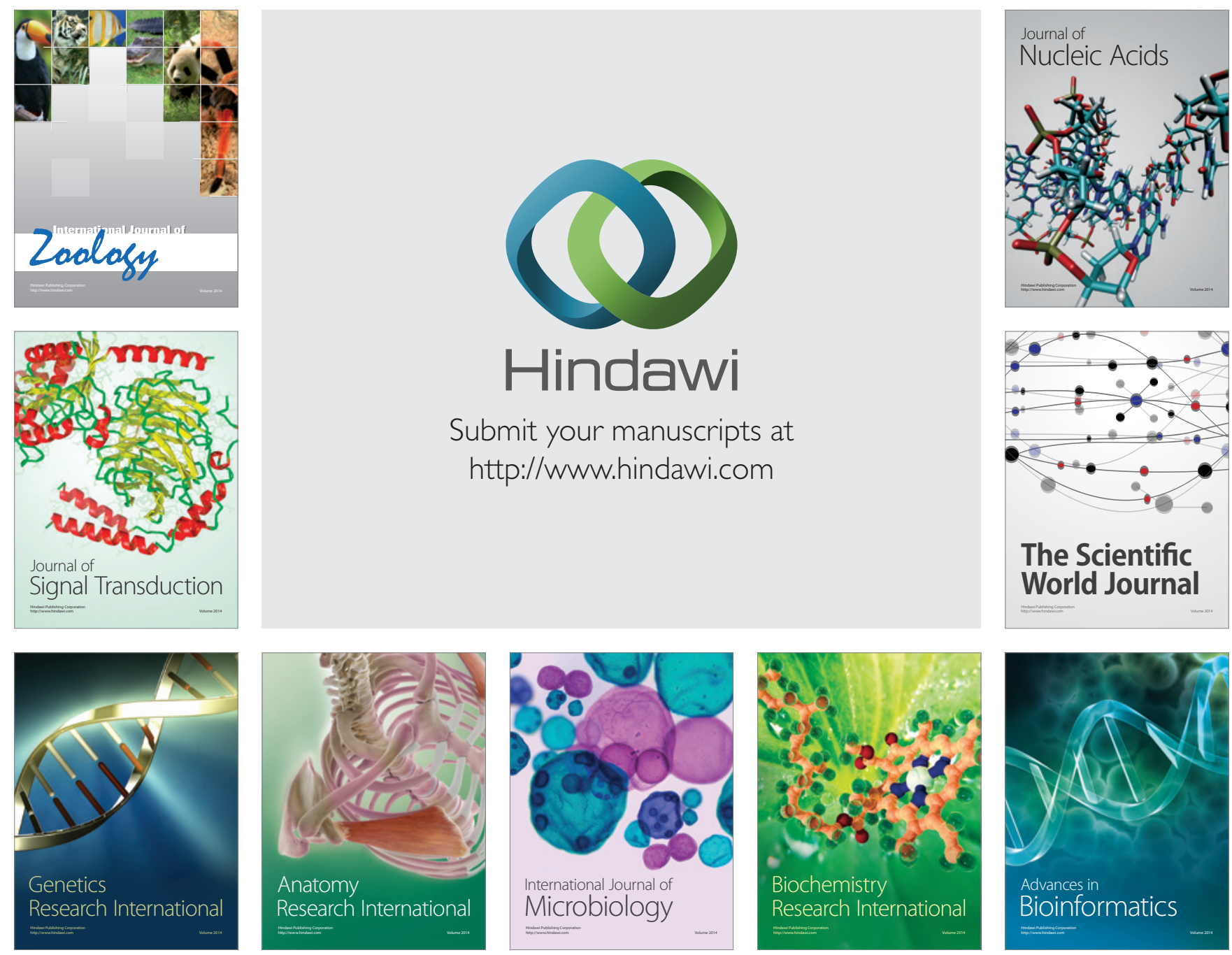

The Scientific World Journal
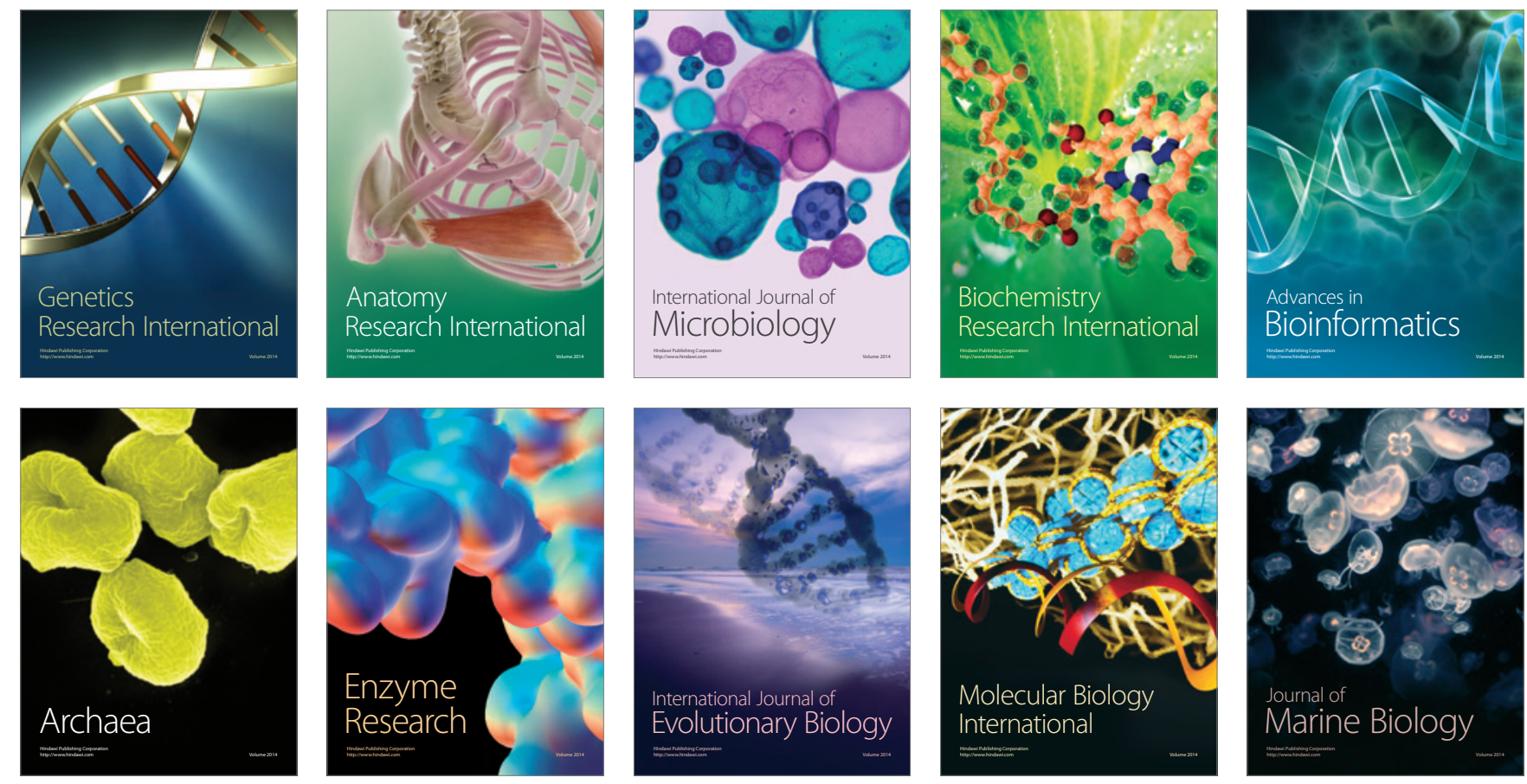